\title{
The enthalpies of combustion and formation of [2.2]-paracyclophane and triptycene
}

\author{
DAVID L. RODGERS, EDGAR F. WESTRUM, JR., \\ and JOHN T. S. ANDREWS ${ }^{a}$ \\ Department of Chemistry, University of Michigan, \\ Ann Arbor, Michigan 48104, U.S.A.
}

(Received 5 May 1972; in revised form 16 February 1973)

\begin{abstract}
The enthalpies of combustion, $\Delta H_{\mathrm{c}}^{\circ}$, for crystalline [2.2]-paracyclophane $\left(\mathrm{C}_{16} \mathrm{H}_{16}\right)$ and triptycene $\left(\mathrm{C}_{20} \mathrm{H}_{14}\right)$ have been measured by oxygen combustion calorimetry. The derived standard enthalpies of formation at $298.15 \mathrm{~K}$ in the crystalline state are $(34.59 \pm 0.19)$ and $(51.87 \pm 0.20) \mathrm{kcal}_{\mathrm{th}} \mathrm{mol}^{-1}$. The strain present in these molecular systems is discussed.
\end{abstract}

\section{Introduction}

The macrocyclic hydrocarbon [2.2]-paracyclophane $\left(\mathrm{C}_{16} \mathrm{H}_{16}\right.$, cyclo-di-p-xylylene, figure 1) is of thermodynamic interest since geometrical constraint ${ }^{(1-3)}$ distorts the planarity of the aromatic rings and may engender strain relief by conformational

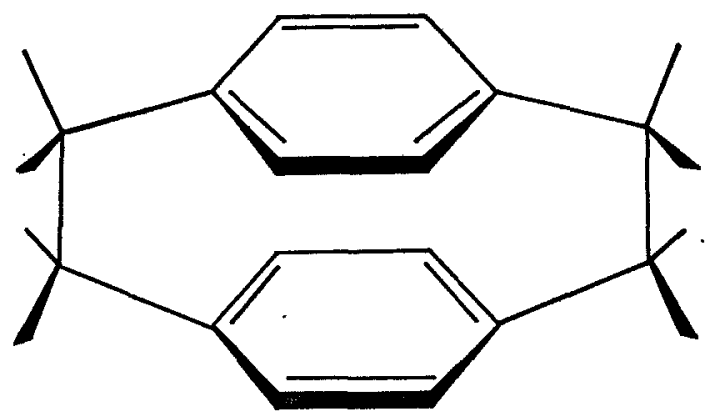

FIGURE 1. Paracyclophane.

twist. ${ }^{(3-5)}$ Although a value for the enthalpy of combustion, $\Delta H_{\mathfrak{c}}^{\circ}$, for [2.2]-paracyclophane has been reported ${ }^{(6)}$ and the strain in the system apportioned between component contributions, the availability of a well-characterized sample for which thermal measurements have been reported, ${ }^{(4)}$ permitted independent redetermination of the thermochemical properties and strain for this system. Determination of the

${ }^{a}$ Present address: Liquid Crystal Institute, Kent State University, Kent, Ohio. 
thermochemistry for triptycene $\left(\mathrm{C}_{20} \mathrm{H}_{14}, 9,10\right.$-o-benzeno-9,10-dihydroanthracene, figure 2) was undertaken to provide a better basis for interpreting the strain in the parent [2.2.2]-bicyclo-octane system. ${ }^{(7)}$

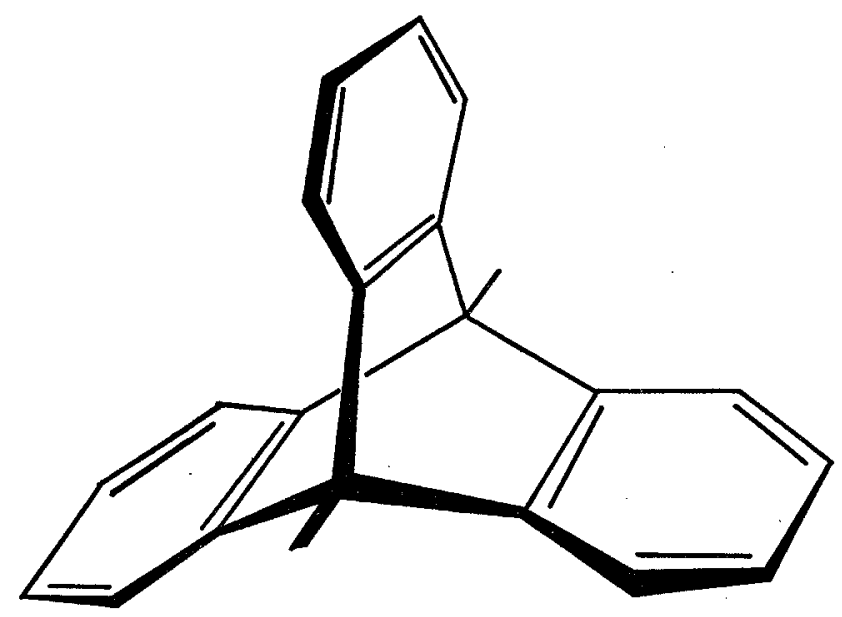

FIGURE 2. Triptycene.

\section{Experimental}

\section{MATERIALS}

Samples of both substances were purified by previously described techniques. ${ }^{(4,8)}$ [2.2]-Paracyclophane, which polymerizes readily above $410 \mathrm{~K}$, was purified by a series of six vacuum sublimations; triptycene was purified by zone-melting, and fractional-fusion experiments indicated 0.001 mole per cent liquid-soluble solidinsoluble impurity. ${ }^{(8,9)}$

\section{CALORIMETRIC PROCEDURE}

The calorimetric system has been described in detail elsewhere. ${ }^{(10)}$ Both samples were burned as pellets in a baffle-covered platinum crucible and were ignited by measured discharge of electrical energy and unmercerized cotton fuse (empirical formula $\left.\mathrm{CH}_{1.686} \mathrm{O}_{0.843},-\Delta E_{\mathrm{c}}^{\circ} / M=4108 \mathrm{cal}_{\mathrm{th}} \mathrm{g}^{-1}\right) . \dagger$ Bomb rotation was initiated at the mid-point of the temperature rise and was continued throughout the remainder of the calorimetric experiment. Temperatures were measured with stainless-steelsheathed platinum-resistance thermometers and a G-2 Müller bridge. After each experiment, the bomb solution was titrated with $0.01 \mathrm{~mol} \mathrm{dm}^{-3}$ sodium hydroxide in the presence of methyl orange indicator to determine the nitric acid equivalent. ${ }^{(1)}$ Data reduction and correction to standard state conditions were performed by digital computer.

$\dagger$ Throughout this paper $\mathrm{cal}_{\mathrm{th}}=4.184 \mathrm{~J}$. 


\section{CALIBRATION}

National Bureau of Standards benzoic acid, sample 39i, $-\Delta E_{\mathrm{c}}^{\circ} / M=(26434.0 \pm 3.3)$ $\mathrm{J} \mathrm{g}^{-1},{ }^{(12)}$ was used to determine the energy equivalent of the calorimetric system. For triptycene, the bomb (laboratory designation NR-2) had an internal volume $0.3520 \mathrm{dm}^{3}$ and the energy equivalent of the system (Series 1) based upon five determinations $(3992.65,3992.82,3992.92,3993.05,3993.35)$, yields an average value $(3992.96 \pm 0.24) \mathrm{cal}_{\text {th }} \mathrm{K}^{-1}$. The precision index is twice the overall standard deviation $^{(13)}$ of the mean value. For [2.2]-paracyclophane, the internal volume of the same bomb was $0.3517 \mathrm{dm}^{3}$ and the energy equivalent of the system (Series II) based upon five determinations $(3995.05,3995.08,3995.20,3995.10,3995.27)$ yields an average value $(3995.14 \pm 0.08) \mathrm{cal}_{\mathrm{th}} \mathrm{K}^{-1}$ with similarly defined precision index.

\section{UNITS AND AUXILIARY QUANTITIES}

The 1962 scale of atomic weights ${ }^{(14)}$ was used and the ice point was taken as $273.15 \mathrm{~K}$. The values for parameters used to correct standard state conditions are given in table 1 and were obtained from the literature, or estimated from those of similar

TABLE 1 . Values of density $\rho$, specific heat capacity $c_{p}$, and temperature coefficient of specific volume, $(\partial v / \partial T)_{p}$

$$
\left(\mathrm{cal}_{\mathrm{th}}=4.184 \mathrm{~J}\right)
$$

\begin{tabular}{lccc}
\hline Substance & $\frac{\rho}{\mathrm{g} \mathrm{cm}^{-3}}$ & $\frac{c_{p}}{\mathrm{cal}_{\text {th }} \mathrm{K}^{-1} \mathrm{~g}^{-1}}$ & $\frac{10^{6}(\partial v / \partial T)_{p}}{\mathrm{dm}^{3} \mathrm{~K}^{-1} \mathrm{~g}^{-1}}$ \\
\hline $\begin{array}{l}\text { [2.2]-Paracyclophane } \\
\text { Triptycene }\end{array}$ & 1.229 & 0.290 & $0.50^{a}$ \\
& 1.227 & 0.266 & $\mathbf{0 . 7 2}^{b}$ \\
\hline
\end{tabular}

${ }^{a}$ Estimated value.

${ }^{b}$ Estimated value for [2.2.2]-bicyclo-octane. ${ }^{(7)}$

materials. Enthalpies of formation, $\Delta H_{\mathrm{f}}^{\circ}$, for $\mathrm{CO}_{2}(\mathrm{~g})$ and $\mathrm{H}_{2} \mathrm{O}(\mathrm{l})$ were the recommended values $-(94.051 \pm 0.010) \mathrm{kcal}_{\text {th }} \mathrm{mol}^{-1},^{(15,16)}$ and $-(68.315 \pm 0.010) \mathrm{kcal}_{\text {th }}$ $\mathrm{mol}^{-1}$ (16)

\section{Results and discussion}

\section{CALORIMETRIC RESULTS}

Eight combustions on paracyclophane and six combustions on triptycene were used to compute average values for $-\Delta E_{\mathrm{c}}^{\circ} / M$ and the derived quantities. Results from typical combustions for each substance are summarized in table 2 . The results of the individual combustion experiments, in terms of $-\Delta E_{\mathrm{c}}^{\circ} / M$ at $298.15 \mathrm{~K}$ are: [2.2]-paracyclophane: $10002.93,10000.95,10001.95,10002.95,10000.89,10003.34,10002.22,10004.47$ $\mathrm{cal}_{\mathrm{th}} \mathrm{g}^{-1}$; average value: $(10002.45 \pm 0.77) \mathrm{cal}_{\text {th }} \mathrm{g}^{-1}$; triptycene: $9472.37,9472.65$, 
TABLE 2. Results of typical combustion experiments $\left(\mathrm{cal}_{t \mathrm{~h}}=4.184 \mathrm{~J}\right)$

\begin{tabular}{|c|c|c|}
\hline Compound & [2.2]-Paracyclophane & Triptycene \\
\hline$m^{\prime}$ (sample) $/ \mathrm{g}$ & 0.667081 & 0.697968 \\
\hline$m^{\prime \prime \prime}$ (fuse) $/ \mathrm{g}$ & 0.001767 & 0.001694 \\
\hline$m^{\prime}\left(\mathrm{H}_{2} \mathrm{O}\right) / \mathrm{g}$ & 1.06 & 1.06 \\
\hline$T_{1} / \mathrm{K}-273.15$ & 23.27322 & 23.28671 \\
\hline$T_{\mathrm{f}} / \mathrm{K}-273.15$ & 24.97205 & 24.97015 \\
\hline$\Delta T_{\mathrm{c}} / \mathrm{K}$ & 1.68994 & 1.67559 \\
\hline$\Delta E_{\mathrm{ign}} / \mathrm{cal}_{\mathrm{th}}$ & 0.27 & 0.28 \\
\hline$\Delta E$ (Washburn corr.)/cal $\mathrm{ch}_{\mathrm{th}}$ & 2.76 & 3.33 \\
\hline$\Delta E_{\mathrm{deo}}\left(\mathrm{HNO}_{3}\right) / \mathrm{cal}_{\mathrm{th}}$ & 0.97 & 0.96 \\
\hline$\Delta E_{\text {soin }}\left(\mathrm{CO}_{2}\right) / \mathrm{cal}_{\text {th }}$ & 0.64 & 0.64 \\
\hline$\Delta E_{\mathrm{dHIn}} / \mathrm{cal}_{\mathrm{th}}$ & 0 & $\mathbf{0}$ \\
\hline$m^{\prime \prime}\left(\Delta E_{\mathrm{c}}^{\circ} / M\right)($ fuse $) / \mathrm{cal}_{\mathrm{th}}$ & 7.26 & 6.96 \\
\hline$\left(\Delta E_{\mathrm{o}}^{\circ} / M\right)($ sample $) / \mathrm{cal}_{\mathrm{th}} \mathrm{g}^{-1}$ & 10001.95 & 9472.13 \\
\hline
\end{tabular}

9472.65, 9471.89, 9470.91, 9471.71 $\mathrm{cal}_{\mathrm{th}} \mathrm{g}^{-1}$; average value: $(9472.02 \pm 0.66) \mathrm{cal}_{\mathrm{th}} \mathrm{g}^{-1}$, and refer to the reaction:

$$
\mathrm{C}_{16} \mathrm{H}_{16}(\mathrm{c})+20 \mathrm{O}_{2}(\mathrm{~g})=16 \mathrm{CO}_{2}(\mathrm{~g})+8 \mathrm{H}_{2} \mathrm{O}(\mathrm{l})
$$

for [2.2]-paracyclophane, and

$$
\mathrm{C}_{20} \mathrm{H}_{14}(\mathrm{c})+23.5 \mathrm{O}_{2}(\mathrm{~g})=20 \mathrm{CO}_{2}(\mathrm{~g})+7 \mathrm{H}_{2} \mathrm{O}(\mathrm{l})
$$

for triptycene.

\section{Derived results}

Average values for derived thermodynamic quantities at $298.15 \mathrm{~K}$ are summarized in table 3. The values $\Delta H_{\mathrm{f}}^{\circ}(\mathrm{c}), \Delta S_{\mathrm{f}}^{\circ}(\mathrm{c})$, and $\Delta G_{\mathrm{f}}^{\circ}(\mathrm{c})$ are derived from the measured-values, the recommended values ${ }^{(16)}$ for $\Delta H_{\mathrm{f}}^{\circ}\left(\mathrm{CO}_{2}, \mathrm{~g}\right), \Delta H_{\mathrm{f}}^{\circ}\left(\mathrm{H}_{2} \mathrm{O}, 1\right), S^{\circ}$ (graphite), $S^{\circ}\left(\mathrm{H}_{2}, \mathrm{~g}\right)$, and the recently published values ${ }^{(3,9)}$ of $S^{\circ}$ for the compounds. Boyd's preferred

TABLE 3. Derived quantities

$\left(\mathrm{cal}_{\mathrm{th}}=4.184 \mathrm{~J}\right)$

\begin{tabular}{lcc}
\hline & Paracyclophane & Triptycene \\
\hline$\Delta E_{\mathrm{c}}^{\circ}(\mathrm{c}) / \mathrm{kcal}_{\mathrm{th}} \mathrm{mol}^{-1 a}$ & $-2083.57 \pm 0.15$ & $-2409.06 \pm 0.28$ \\
$\Delta H_{\mathrm{o}}^{\circ}(\mathrm{c}) / \mathrm{kcal}_{\mathrm{th}} \mathrm{mol}^{-1}$ & $-2085.94 \pm 0.15$ & $-2411.13 \pm 0.28$ \\
$\Delta H_{\mathrm{f}}^{\circ}(\mathrm{c}) / \mathrm{kcal}_{\mathrm{th}} \mathrm{mol}^{-1}$ & $34.59 \pm 0.21$ & $51.90 \pm 0.30$ \\
$\Delta S_{\mathrm{f}}^{\circ}(\mathrm{c}) / \mathrm{cal}_{\mathrm{th}} \mathrm{K}^{-1} \mathrm{~mol}^{-1}$ & $-207.96 \pm 0.10$ & $-180.22 \pm 0.12$ \\
$\Delta G_{\mathrm{f}}^{\mathrm{o}}(\mathrm{c}) / \mathrm{kcal}_{\mathrm{th}} \mathrm{mol}^{-1}$ & $96.60 \pm 0.20$ & $105.60 \pm 0.22$ \\
$\Delta H_{\mathrm{v}}^{\circ}(298.15 \mathrm{~K}) / \mathrm{kcal}_{\mathrm{th}} \mathrm{mol}^{-1}$ & $23 \pm 1^{\mathrm{b}}$ & $25 \pm 3^{\mathrm{o}}$ \\
$\Delta H_{\mathrm{f}}^{\circ}(\mathrm{g}) / \mathrm{kcal}_{\mathrm{th}} \mathrm{mol}^{-1}$ & $57.6 \pm 1$ & $76.9 \pm 3$ \\
\hline
\end{tabular}

"Precision index as previously defined.

${ }^{\circ}$ Compare reference 6.

c We are indebted to Dr. Melvin Neuman of Dow Chemical Company for an estimate of the enthalpy of sublimation for triptycene in advance of publication. 
value $-(2088.2 \pm 0.9) \mathrm{kcal}_{\mathrm{th}} \mathrm{mol}^{-1}$ for $\Delta H_{\mathrm{c}}^{\circ}$ (c) for paracyclophane ${ }^{(6)}$ differs somewhat from the present value $-(2085.94 \pm 0.16) \mathrm{kcal}_{\mathrm{th}} \mathrm{mol}^{-1}$; no value for triptycene has been reported.

\section{Discussion}

A reference value, $\Delta H_{\mathrm{f}}^{\circ}(\mathrm{g}$, ref.), can be calculated for [2.2]-paracyclophane by the method of group increments, ${ }^{(18)}$ which accounts for bond energies and substituent group interactions but ignores the energetic effects of molecular distortion. This value, $28.2 \mathrm{kcal}_{\mathrm{th}} \mathrm{mol}^{-1}$, when compared with the experimental value, $57.6 \mathrm{kcal}_{\mathrm{th}} \mathrm{mol}^{-1}$, suggests that the total strain energy in [2.2]-paracyclophane is approximately $29 \mathrm{kcal}_{\mathrm{th}} \mathrm{mol}^{-1}$. The origin of this sizeable strain energy seems to rest with [2.2]paracyclophane's distorted geometry, the consequences of which is the dishing of the benzene rings, and the elongation of the bridging bonds, all of which are obvious features of the X-ray structure. ${ }^{(1,2)}$

Another procedure for obtaining a qualitative estimate of the total strain energy, first suggested by Boyd ${ }^{(6)}$ involves comparison of the enthalpy of hydrogenation of [2.2]-paracyclophane with that for the symmetrical cleavage of 1,2-diphenylethane under similar conditions. The results, together with an estimate for the total strain energy are summarized in table 4 . As is readily seen, the results by the different methods are in reasonable accord and compare favorably with an a priori estimate, $33 \mathrm{kcal}_{\text {th }}$ $\mathrm{mol}^{-1}$, by Trueblood (compare reference 6 ).

In Boyd's analysis, ${ }^{(6)}$ the $4 \mathrm{kcal}_{\mathrm{th}} \mathrm{mol}^{-1}$ of total strain energy in paracyclophane which he assigns to eclipsed-hydrogen interactions may need downward revision in light of the observation made by some of us ${ }^{(4,8)}$ that there appears to be an anomaly in the low-temperature heat capacity at $50 \mathrm{~K}$ which suggests the possibility of strain relief by twisting. In the twisted conformation, the contribution of eclipsed-hydrogen interactions to the total strain energy in the molecule would tend to be reduced. Additional support for the "twist" conformation can be found in recent spectroscopic $^{(5)}$ and X-ray results. ${ }^{(3)}$ For [2.2.2]-bicyclo-octane, where the skeleton is rigid, this mode of strain relief is not observed ${ }^{(20)}$ and, therefore, eclipsed-hydrogen interactions make a full contribution to the total strain energy in the system.

The strain energy in triptycene may be evaluated in an analogous manner. The reference value $\Delta H_{\mathrm{f}}^{\circ}\left(\mathrm{g}\right.$, ref.) calculated by group increments gives $70.2 \mathrm{kcal}_{\mathrm{th}} \mathrm{mol}^{-1}$ and a comparison with the experimental value $76.8 \mathrm{kcal}_{\mathrm{th}} \mathrm{mol}^{-1}$ suggests that the total strain energy in triptycene is approximately $7 \mathrm{kcal}_{\mathrm{th}} \mathrm{mol}^{-1}$. The "direct comparison" method, involving in each case, hydrogenation of three carbon-hydrogen bonds to three phenyl-hydrogen bonds is illustrated in table 5. That the reaction for triptycene is more energetic suggests that triptycene is, in fact, strained. Once again, the magnitude of total strain energy by independent methods is within reasonable accord and within the uncertainty imposed by lack of an experimental value for the enthalpy of vaporization, $\Delta H_{\mathrm{v}}^{\circ}$, for triptycene at $298.15 \mathrm{~K}$.

In bicyclo-[2.2.2]-octane, the contribution of angular strain is a minor component to the total strain energy; most of the strain has its origin in the three eclipsedhydrogen interactions. ${ }^{(7,21)}$ Triptycene may be presumed to be a rigid structure 49* 


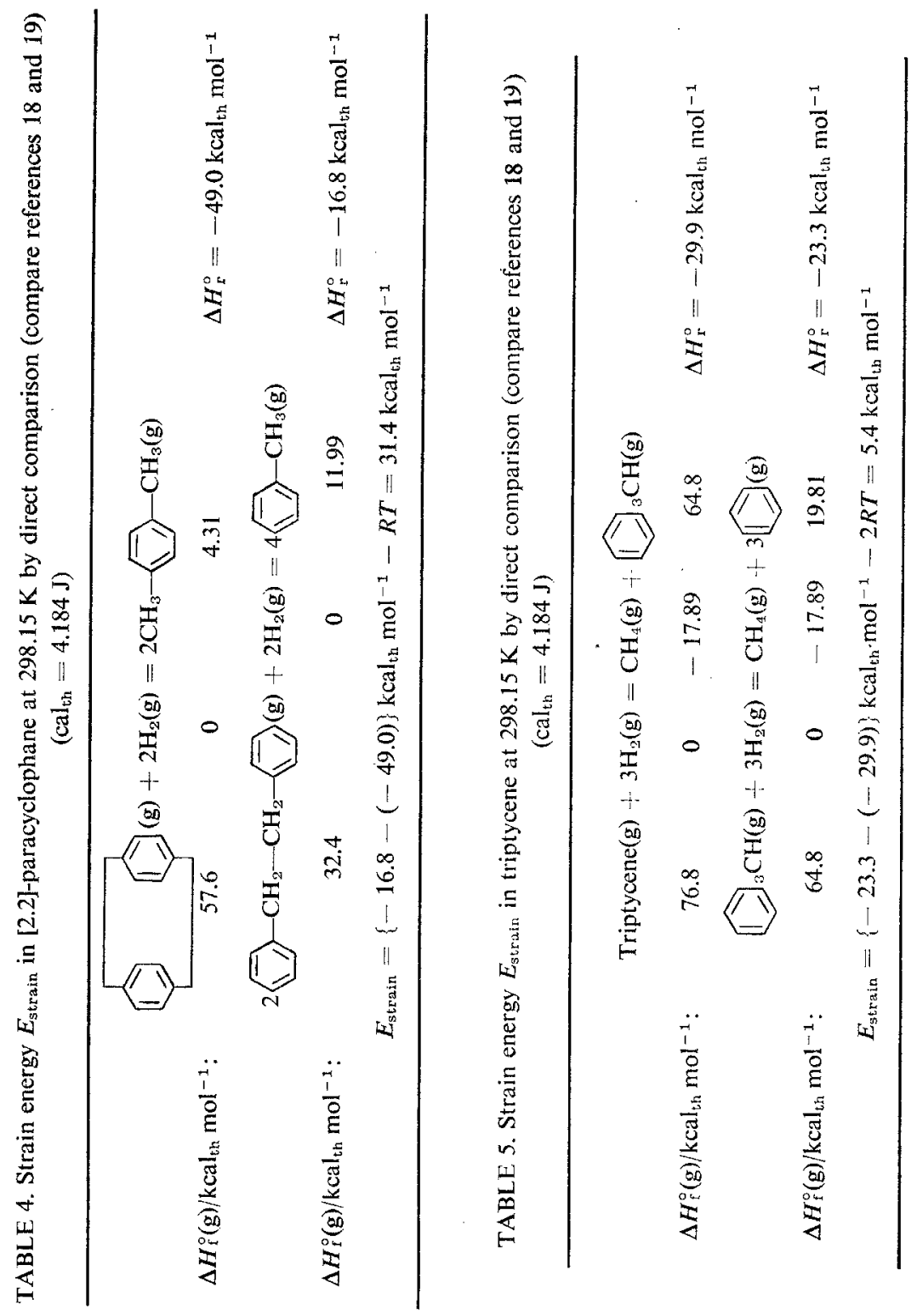


devoid of eclipsed-hydrogen interactions if we adopt the suggestion that transannular interactions ${ }^{(22)}$ and partial bond fixation ${ }^{(23)}$ make a negligible contribution to the ground state. By analogy with 1-bromotriptycene ${ }^{(24)}$ and $\beta$-bromo-1-ethyl triptycene, ${ }^{(25)}$ the origin of the strain in triptycene must reside in the bicyclo-octane system as a result of the angular distortion between the bridgehead carbon atoms and the aromatic moieties.

This work was initiated by the U.S. Atomic Energy Commission and support continued by the National Science Foundation. We thank C. H. Shomate of the Naval Ordinance Test Station, China Lake, California and W. D. Good of the Bartlesville Energy Research Center, Bartlesville, Oklahoma, for the development of the digital computer program which we adapted to our computer system.

\section{REFERENCES}

1. Brown C. J. J. Chem. Soc. 1953, 3265.

2. Lonsdale, K.; Milledge, H. J.; Rao, K. V. K. Proc. Roy. Soc. 1960, A255, 82.

3. Hope, H.; Trueblood, K. N. Acta Cryst. 1972, B28, 1733.

4. Andrews, J. T. S.; Westrum, E. F., Jr. J. Phys. Chem. 1970, 74, 2170.

5. Ron, A.; Schnepp, O. J. Chem. Phys. 1962, 37, 2540.

6. Boyd, R. H. Tetrahedron 1966, 22, 119.

7. Wong, S.; Westrum, E. F., Jr. J. Amer. Chem. Soc. 1971, 93, 5317.

8. Andrews, J. T. S., Ph.D. Thesis, University of Michigan, Ann Arbor, 1969.

9. Andrews, J. T. S.; Westrum, E. F., Jr. J. Chem. Thermodyn. 1970, 2, 245.

10. Månsson, M.; Rapport, N.; Westrum, E. F., Jr. J. Amer. Chem. Soc. 1970, 92, 7296. Good, W. D.; Scott, D.; Waddington, G. J. Phys. Chem. 1956, 60, 1080.

11. Coops, J.; Jessup, R. S.; Van Nes, K. In Experimental Thermochemistry. Chap. 3. Rossini, F, D.; editor. Interscience, J. Wiley \& Sons: New York. 1956.

12. Churney, K. K.; Armstrong, G. T. J. Res. Nat. Bur. Stand. 1968, 72A, 453.

13. Reference 11, Chap. 14.

14. Cameron, A. E.; Wichers, E. J. Amer. Chem. Soc. 1962, 84, 4175.

15. Prosen, E. J.; Jessup, R. S.; Rossini, F. D. J. Res. Nat. Bur. Stand. 1944, 33, 447.

16. ICSU-CODATA Task Group, Report on key values for thermodynamics. J. Chem. Thermodynamics 1972, 4, 331.

17. Stull, D. R.; Westrum, E. F., Jr.; Sinke, G. C. The Chemical Thermodynamics of Organic Compounds. J. Wiley \& Sons: New York. 1969.

18. Cox, J. D.; Pilcher, G. Thermochemistry of Organic and Organometallic Compounds. Academic Press: New York. 1970, 590.

19. Nelander, B.; Sunner, S. J. Chem. Phys. 1966, 44, 2476.

20. Wong, W. K.; Westrum, E. F., Jr. J. Phys. Chem. 1970, 74, 1303.

Yokozeki, A.; Kuchitsu, K.; Morino, Y. Bull. Chem. Soc. (Japan). 1970, 43, 2017.

21. Gleicher, G. J.; Schleyer, P. V. R. J. Amer. Chem. Soc. 1967, 89, 582.

22. Wilcox, C. F. J. Chem. Phys. 1960, 33, 1874.

23. Cooper, M. A.; Manatt, S. L. J. Amer. Chem. Soc. 1970, 92, 1605.

24. Estlin, J. A.; Karle, I. L. Amer. Cryst. Assoc. Winter Meeting Abs. F4. Atlanta, Georgia. 1967.

25. Palmer, K. J.; Templeton, D. H. Acta Cryst. 1968, B24, 1048.

26. Hazell, R. G.; Pawley, G. S.; Lund-Petersen, C. E. J. Cryst. Mol. Struct. 1971, 1, 319. 